\title{
Leprosy researchers lament suppression of Indian paper
}

New Delhi \& Washington. Professional jealousy has for more than a decade blocked publication of a paper on leprosy that could have hastened progress on finding an animal model indigenous to India, where the disease is most prevalent.

\section{IMAGE UNAVAILABLE FOR COPYRIGHT REASONS}

The slender loris is common in southern India.

A group of Indian and US scientists working at JIPMER (the Jawaharlal Nehru Institute for Postgraduate Medical Education and Research) in Pondicherry found that leprosy could be experimentally transmitted to the slender loris, a species of monkey easily obtainable in southern India. At the time researchers were looking for an alternative to the armadillo, which is expensive and not native to Asia.

The 1981 article was accepted by the International Journal of Leprosy pending resolution of a dispute over authorship. An influential microbiologist at the institute, S.C. Agarwal, insisted on being listed first; his co-authors, including Waldemar Kirchheimer, then of the US Public Health Service hospital in Carville, Louisiana, and B.M.S. Bedi and E. Narayanan of JIPMER, objected on the grounds that Agarwal had not been involved in the experiment.

The journal's editor, Robert Hastings, says that he asked Agarwal to "clear up the flap" but that Agarwal never replied. Three years later, Agarwal refused to allow another scientist to present the results at a World Leprosy Congress in Agra, India, and to this day they have remained unpublished.

Agarwal's former colleagues say that they have finally decided to speak up because such conduct should be exposed and condemned by the scientific community and because they are saddened by the loss of an important animal model for leprosy research. There is also the matter of professional pride. "It was in our grasp to be the first to receive credit [for documenting experimental leprosy in a colony of some 100 lorises inoculated with Mycobacterium leprae]", says one scientist.

The work did not advance to the stage where vaccines against the disease could be tested. "The loris was a new experimental animal and a lot of basic work had to be done before inoculation could begin", says Bedi, the principal investigator of the US-Indian project for several years and now a skin specialist in a Delhi hospital. The published work was to be based on observations over a few years of a spreading form of leprosy.

But the observations lasted for only six months. Agarwal, who was about to leave the institute, assumed control of the project from Bedi's successor, M.N. Ghosh, and killed the 66 surviving animals. "Agarwal destroyed valuable evidence of the progressive development of the disease in loris in order to grab credit for himself before he left", says one researcher who requested anonymity.

Agarwal denies that he acted improperly and says that he deserves to be listed as first author because he was the principal investigator when the research ended and because he was the one to detect leprosy transmis- sion. "If these lorises had not been detected by me, there would have been no findings, no publication and no controversy". He also says that he killed only five of the research monkeys and that the rest died of natural causes.

Kirchheimer, now retired, disputes Agarwal's account, saying that Agarwal "knew nothing about leprosy" and "had no interest in the disease". He says that Agarwal acted out of "jealousy and disappointment" after failing to succeed M. Balasubramanian as director of JIPMER.

Curiously, Kirchheimer was himself involved in a celebrated dispute in the late 1970 s over the discovery of several natural cases of leprosy in armadillos in the southwestern United States. Kirchheimer accused scientists at a research institute in Louisiana of allowing infected animals to escape and of causing the artificial spread of the disease. Although that charge has since been refuted, Kirchheimer remains critical of what he sees as widespread unethical conduct among some of his former colleagues.

One veteran research who was surprised to hear about the Indian research was Robert Gormas, who has worked at the Delta Primate Center in Louisiana for 14 years, successfully transmitting the disease to dozens of sooty mangabees and rhesus monkeys. More recently, he has discovered two natural cases of leprosy in sooty mangabees.

He says that Bedi's work "could have been used widely" if it showed that the slender loris was a useful model. Wayne Meyers, of the US Air Force Institute of Pathology in Washington, DC, says that researchers "are still looking for an animal model that is easily maintained, readily accessible and relatively inexpensive" and that it would be a boon to Indian researchers if the loris filled the bill.

K.S. Jayaraman \& Jeffrey Mervis

\section{McBride found guilty of fraud}

Sydney. William McBride, the Australian researcher credited with issuing the first warning of the dangers of the drug Thalidomide, has been declared guilty of scientific fraud.

The medical tribunal of the state of New South Wales last week found McBride guilty of falsifying the results of an experiment to establish whether the morning sickness drug Denebox, produced by Merrell Dow, causes birth deformities. The tribunal dismissed all but one of a number of charges relating to the separate issue of McBride's conduct as a gynaecologist, and described that one proven charge as a "minor lapse". The tribunal will determine a penalty after McBride's defence lawyers and the state health department prosecutors have studied the lengthy judgement.
An inquiry set up in 1988 by the research centre founded by McBride, Foundation 41, found that he had altered the results of an otherwise inconclusive experiment on 16 rabbits. The inquiry found that McBride had changed the drug doses, added rabbits and a control group and identified non-existent abnormalities in the rabbit fetuses in an attempt to show that the drug is dangerous.

The case has forced researchers and government officials to pay closer attention to the issue of scientific misconduct. The Australian National Health and Medical Research Council now requires institutions applying for grants to have procedures in place for dealing with allegations of scientific misconduct.

Mark Lawson 